\title{
Contactless Food Supply and Delivery System in the COVID-19 Pandemic: Experience from Raytheon Mountain Hospital, China
}

This article was published in the following Dove Press journal: Risk Management and Healthcare Policy

Xiaodong Tan ${ }^{1,2}$

Li $\operatorname{Ran}^{2}$

Fucui Liao ${ }^{3}$

'School of Nursing, Wuchang University of Technology, Wuhan, People's Republic of China; ${ }^{2}$ School of Health Sciences, Wuhan University, Wuhan, People's Republic of China; ${ }^{3}$ Department of Medical Insurance and Management, Zhongnan Hospital of Wuhan University, Wuhan, People's Republic of China

Correspondence: Xiaodong Tan Wuchang University of Technology, Wuhan, People's Republic of China Email00300469@whu.edu.cn

Fucui Liao

Zhongnan Hospital of Wuhan University, Wuhan, People's Republic of China Email37|381804@qq.com

\begin{abstract}
The contactless food supply and delivery system of Raytheon Mountain Hospital is an innovative action to solve the dining problem and balance nutrition for medical staff and patients. The system was established according to five approval criteria, including localization, experience in hospital meal service, sufficient raw materials and supporting facilities, food safety, and high execution in dispatching. From the preparation phase to service optimization and improvement, the service model of the full collection of food and beverage information, point-to-point distribution, contactless food delivery, one-stop ordering, and full coverage of separately eating is established to safeguard the contactless food supply and delivery system operating smoothly. As of April 15, 2020 Raytheon Mountain Hospital had been operating safely for 68 days with no occurrence of food safety accident. Keywords: COVID-19, food delivery, medical staff, nutrition, Raytheon Mountain Hospital
\end{abstract}

As is known, Wuhan encountered a temporary shortage of supplies in the early lockdown, and it was at that time medical staff and patients faced transient problems of food supply and delivery. ${ }^{1,2}$ Accordingly, the Raytheon Mountain Hospital, a temporary large-scale designated hospital, ${ }^{2}$ was not only built up for treating patients severely affected by coronavirus disease (COVID-19) ${ }^{3,4}$ but also innovatively creating a contactless food supply and delivery system.

Because transmission routes were not fully understood at that time, this system was established with the biggest advantage of noncontact character compared with other online food delivery services. Around this feature, a responsible third-party company was selected with following criteria: (1) local company managed by the government to facilitate the organization and dispatching; (2) relevant experience conducive to rapid anti-epidemic works; (3) sufficient raw materials and corresponding reserves like insulation boxes and meal carts; and (4) accident-free is required to ensure food safety.

In the preparation phase, the Food Management Group with nutritionists developed personalized nutrition prescriptions for medical staff and patients. Nutrition prescriptions were developed under the Dietary Guidelines for Chinese Residents $(2016)^{5}$ and Nutritional Dietary Guidelines for the Prevention and Control of Coronavirus Diseases, ${ }^{6}$ and followed the principles of balance and diversity. In addition, patients' nutrition prescriptions included fluid diet, semi-fluid diet, diabetes diet, low-salt low-fat diet, and high-protein diet, while northeastern Chinese 
cuisine, Shanghai cuisine, Cantonese cuisine, and Muslim meal were developed to cater for medical staff's special taste needs. Furthermore, kitchen and operation were sprayed with disinfectant and lit with ultraviolet light for two hours twice a day, and thermal containers and food carts were wiped with 84 disinfectant three times a day.

Ordering can be done directly via the WeChat application with the instruction of doctors and nurses. WeChat groups were built up with group leaders responsible for counting the mealtimes, set meals, and the number of diners. The full menu expands beyond traditional lunch offerings to encompass breakfast, dinner offerings, and limited snack offerings. After that, food-making was produced by healthy staff, who were required to wash hands with soap or antibacterial hand sanitizer, and then use 1 3 mL quick-drying hand sanitizer to wipe hands. Cooks need to wear masks, apron, kitchen cook paper hat, and disposable gloves.

Meals are separately packed with an insulation box to keep the center temperature over $62^{\circ} \mathrm{C}$ so that deliverymen who show negative nucleic acid tests are responsible for completing all distribution works within $60 \mathrm{~min}$. Considering the transmissibility of COVID- $19,{ }^{3}$ a restricted clean channel was set up in the distribution of meals and the number of deliverymen and meal carts were equipped based on the number of ward beds. Deliverymen strictly abided by the principle of contactless delivery, while a point-to-point delivery was required to avoid deliverymen becoming viral vectors and to avoid heat loss as much as possible.

As of April 15, the contactless food supply and delivery system of Raytheon Mountain Hospital had operated well for 68 days, and it helped to reduce virus transmission to a large extent. Since COVID-19 is still alarming and countries all have invested a great deal of manpower and material resources, ${ }^{7,8}$ we hope this summary can provide an effective reference for other emergency hospitals. To better deal with the continuous epidemic, hospitals in other countries could take similar measures to reduce virus transmission and take active steps to promise wellbalanced nourishment for medical staff and patients.

\section{Disclosure}

The authors report no conflicts of interest in this work.

\section{References}

1. Aizhen Z. Medical Nutrition. 3rd ed. First-version ed: People's Medical Publishing House(PMPH); 2009.

2. People' CN. The Preparation Work of Wuhan Leisehnshan Hospital is in Order. 2020.

3. Zhu N, Zhang D, Wang W, et al. A novel coronavirus from patients with pneumonia in China, 2019. N Engl J Med. 2020;382(8):727-733. doi:10.1056/NEJMoa2001017

4. Chen S, Zhang Z, Yang J, et al. Fangcang shelter hospitals: a novel concept for responding to public health emergencies. Lancet. 2020;395 (10232):1305-1314. doi:10.1016/S0140-6736(20)30744-3

5. Xin S. Dietary guidelines for Chinese residents (2016) has been published. Chin J Woman Child Health Res. 2016;027:670.

6. Chinese Center for Disease Control and Prevention. Nutritional Dietary Guidelines for the Prevention and Control of Coronavirus Diseases. 2020

7. Huynh T. The COVID-19 containment in Vietnam - what are we doing. $J$ Glob Health. 2020;10(1):10338. doi:10.7189/jogh.10.010338

8. Huynh T. Does culture matter social distancing under the COVID-19 pandemic? Saf Sci. 2020;130:104872. doi:10.1016/j.ssci.2020.104872
Risk Management and Healthcare Policy

\section{Publish your work in this journal}

Risk Management and Healthcare Policy is an international, peerreviewed, open access journal focusing on all aspects of public health, policy, and preventative measures to promote good health and improve morbidity and mortality in the population. The journal welcomes submitted papers covering original research, basic science, clinical \& epidemiological studies, reviews and evaluations, guidelines, expert opinion and commentary, case reports and extended reports. The manuscript management system is completely online and includes a very quick and fair peer-review system, which is all easy to use. Visit http://www.dovepress.com/testimonials.php to read real quotes from published authors. 